\title{
KETUNGGALAN TITIK TETAP DI RUANG DISLOCATED QUASI B-METRIK PADA PEMETAAN SIKLIK
}

\author{
Malahayati $^{1}$ \\ Matematika, UIN Sunan Kalijaga, Malahayati_01@yahoo.co.id ${ }^{1}$
}

\begin{abstract}
Abstrak
Ruang dislocated quasi b-metrik (ruang metrik-dqb) pertama kali diperkenalkan oleh Klin-eam dan Suanoom pada tahun 2015. Mereka berhasil membuktikan sifat ketunggalan titik tetap di ruang metrik-dqb pada pemetaan siklik dengan syarat memenuhi kondisi kontraksi Banach siklik. Selanjutnya, pada tahun 2016 Dolicanin dkk menunjukkan bahwa sifat ketunggalan titik tetap di ruang metrik-dqb dapat dibuktikan tanpa mensyaratkan pemetaan tersebut memenuhi kondisi kontraksi Banach siklik. Kedua pernyataan tersebut dibuktikan ekuivalen dalam paper ini.
\end{abstract}

Kata kunci: Ruang dislocated quasi b-metrik, Pemetaan Siklik, Titik Tetap.

\begin{abstract}
The quasi b-metric dislocated space (dqb-metric space) was first introduced by Klin-eam and Suanoom in 2015. They had been proven the uniqueness of the fixed point in the dqb-metric space on cyclic mapping that provide the cyclic Banach contraction conditions. Furthermore, in 2016 Dolicanin et al showed that the fixed point singularity properties in the dqb-metric space can be proven without requiring the mapping to satisfy the cyclic metrics Banach contraction conditions. Both statements are proved equivalent in this paper.
\end{abstract}

Keywords: Dislocated quasi b-metric Space, Cyclic Mapping, Fixed Point

\section{Pendahuluan}

Konsep titik tetap pertama kali digunakan oleh seorang matematikawan Perancis yang bernama Poincare di tahun 1895 sampai 1900. Pada tahun 1910, Brouwer membuktikan bahwa terdapat paling sedikit satu titik tetap untuk pemetaan kontinu polyhedral di ruang berdimensi berhingga, dan inilah yang membuka banyak peluang penelitian mengenai teori titik tetap. Khususnya pada tahun 1922, seorang matematikawan Polandia yang bernama Banach memberikan suatu inovasi penting yang dikenal dengan Prinsip pemetaan kontraksi Banach dengan menggunakan metode iterasi Picard.

Hasil dari pembuktian tersebut telah menjadi aset penting untuk matematika terapan, karena aplikasi dari teori tersebut berperan besar pada berbagai cabang ilmu matematika yang meliputi persamaan diferensial, persamaan integral dan bidang ilmu matematika lainnya, terutama yang melibatkan logika pemrograman dan teknik elektronik.

Terutama dalam beberapa dekade terakhir, dengan perkembangan komputer banyak orang memiliki berbagai aplikasi dengan memanfaatkan berbagai metode iterasi untuk mendekati titik tetap dan oleh karena itu banyak para peneliti membuat terobosan dan berusaha untuk menyempurnakan teori-teori yang sudah ada.

Konsep ruang metrik quasi (quasi- metric spaces) diperkenalkan oleh Wilson [13] pada tahun 1931 dan di tahun 2000 Hitzler dan Seda [14] memperkenalkan ruang metrik terasing (dislocated metric spaces), selanjutnya Zeyada [15] mengembangkan hasil yang telah diperoleh oleh Wilson, Hitzler dan Seda dengan memperkenalkan ruang metrik quasi terasing (dislocated quasi metric spaces). Sedangkan di tahun 1989, Bakhtin [24] memperkenalkan ruang b-metrik (b-metric spaces) selanjutnya 
Czerwik [25] membuat hasil dari Bakhtin tersebut lebih dikenal dan mengembangkannya di tahun 1998. Sampai saat ini, telah banyak peneliti yang mengembangkan konsep ruang bmetrik, diantaranya ruang quasi $b$-metrik, ruang seperti b-metrik (b-metric like spaces) dan ruang seperti quasi b-metrik (quasi -b-metric like spaces).

Belakangan pembahasan yang sedang menarik dan terus mengalami kemajuan adalah mengenai ruang dislocated quasi $b$-metrik (dislocated quasi b-metric spaces) yang diperkenalkan oleh Klin-eam dkk [2] pada tahun 2015, selanjutnya ruang ini di singkat ruang metrik $d q b$ untuk mempermudah penulisan.

Sebelum membahas lebih jauh tentang ruang metrik $d q b$, perlu diingat kembali definisi pemetaan siklik.

Definisi 1.1. Diberikan himpunan-himpunan $A$ dan $B$ masing-masing adalah himpunan bagian tak kosong dari ruang metrik $(X, d)$ dan $T: A \cup$ $B \rightarrow A \cup B$. Pemetaan $T$ disebut pemetaan siklik apabila $T(A) \subseteq B$ dan $T(B) \subseteq A$.

Berikut ini diberikan definisi ruang metrik $d q b$.

Definisi 1.2 Diberikan himpunan tak kosong $X$ dan suatu konstanta $s \geq 1$. Fungsi $d: X \times X \rightarrow$ $[0, \infty)$ memenuhi kondisi:

$(d 1)$. Jika $d(x, y)=d(y, x)=0$ maka $x=y$, untuk semua $x, y \in X$; dan

(d2). $d(x, y) \leq s\{d(x, z)+d(z, y)\}$, untuk semua $x, y, z \in X$;

Pasangan $(X, d)$ disebut ruang metrik dislocated quasi b-metrik (dislocated quasi b-metric spaces) atau disingkat ruang metrik dqb dan bilangan s disebut koofisien dari ruang metrik $d q b(X, d)$.

Berikut ini diberikan contoh ruang metrik $d q b$.

Contoh 1.3 Diberikan $X=\mathbb{R}$ dan didefinisikan

$$
d(x, y)=|x-y|^{2}+\frac{|x|}{n}+\frac{|y|}{m}, n, m
$$$$
\in \mathbb{N} \backslash\{1\}, n \neq m \text {. }
$$

Maka $(X, d)$ merupakan ruang metrik $d q b$ dengan koefisien $s=2$.

Bukti:

Diambil sembarang $x, y, z \in \mathbb{R}$.

$(d 1)$. Jika $d(x, y)=d(y, x)=0$ maka diperoleh

$$
d(x, y)=|x-y|^{2}+\frac{|x|}{n}+\frac{|y|}{m}=0
$$

maka

$$
|x-y|^{2}=0, \frac{|x|}{n}=0, \text { dan } \frac{|y|}{m}=0
$$

Berarti

$$
x=y .
$$

(d2). Akan dibuktikan: $d(x, y) \leq s\{d(x, z)+$ $d(z, y)\}$.

Perhatikan bahwa:

$$
\begin{gathered}
d(x, y)=|x-y|^{2}+\frac{|x|}{n}+\frac{|y|}{m} \\
=|x-z+z-y|^{2}+\frac{|x|}{n}+\frac{|y|}{m} \\
\leq(|x-z|+|z-y|)^{2}+\frac{|x|}{n}+\frac{|y|}{m} \\
\leq 2\left(|x-z|^{2}+|z-y|^{2}\right)+\frac{|x|}{n}+\frac{|y|}{m} \\
\quad+\frac{|z|}{m}+\frac{|z|}{n} \\
\leq 2\left\{\left(|x-z|^{2}+\frac{|x|}{n}+\frac{|z|}{m}\right)\right. \\
\left.\quad+\left(|z-y|^{2}+\frac{|z|}{n}+\frac{|y|}{m}\right)\right\} \\
=2\{d(x, z)+d(z, y)\}
\end{gathered}
$$

Dengan memilih $s=2$, maka pernyataan terbukti.

Selanjutnya akan diberikan definisi barisan konvergen dan barisan Cauchy di ruang metrik $d q b$.

Definisi 1.4 Diberikan ruang metrik $d q b(X, d)$ dan barisan $\left\{x_{n}\right\}$ di $(X, d)$.

a. Barisan $\left\{x_{n}\right\}$ dikatakan konvergen-dqb (dislocated quasi b-converges) ke $x \in X$ apabila

$$
\lim _{n \rightarrow \infty} d\left(x_{n}, x\right)=0=\lim _{n \rightarrow \infty} d\left(x, x_{n}\right)
$$

Dalam hal ini, $x$ disebut limit-dqb barisan $\left\{x_{n}\right\}$ dan ditulis $\left(x_{n} \rightarrow x\right)$

b. Barisan $\left\{x_{n}\right\}$ disebut barisan Cauchy-dqb apabila berlaku

$$
\lim _{m, n \rightarrow \infty} d\left(x_{n}, x_{m}\right)=0=\lim _{m, n \rightarrow \infty} d\left(x_{m}, x_{n}\right)
$$

c. Ruang metrik-dqb $(X, d)$ dikatakan lengkap apabila setiap barisan Cauchy-dqb merupakan barisan konvergen-dqb di dalam $X$.

Sebelum membahas teorema-teorema utama dalam paper ini, berikut diberikan terlebih dahulu definisi kontraksi Banach siklik- $d q b$. 
Definisi 1.5 Diberikan ruang metrik $d q b(X, d)$, dengan $A, B \subseteq X$. Pemetaan siklik $T: A \cup B \rightarrow$ $A \cup B$ dikatakan kontraksi Banach siklik-dqb (dqb-cyclic-Banach Contraction) apabila terdapat $k \in\left[0, \frac{1}{s}\right), s \geq 1$ sehingga berlaku $d(T x, T y) \leq k d(x, y)$

Untuk setiap $x \in A, y \in B$.

\section{Pembahasan}

Pada bagian ini akan dibahas teorema ketunggalan titik tetap di ruang metrik $d q b$, sebelumnya diberikan lemma yang akan digunakan dalam membuktikan teorema tersebut.

Lemma 2.1. Diberikan ruang metrik $d q b$ lengkap $(X, d)$ dan $\left\{A_{i}\right\}_{i=1}^{p}$ keluarga himpunan bagian tertutup tak kosong di X. Jika pemetaan $T: \bigcup_{i=1}^{p} A_{i} \rightarrow \bigcup_{i=1}^{p} A_{i}$ memenuhi kondisi:

1) $T\left(A_{i}\right) \subseteq A_{i+1}$, untuk setiap $1 \leq i \leq p$ dengan $A_{p+1}=A_{1}$;

2) Terdapat $k \in\left[0, \frac{1}{s}\right)$ sehingga untuk setiap $x \in \cup_{i=1}^{p} A_{i}$, berlaku $d\left(T^{2} x, T x\right) \leq k d(T x, x)$, $d\left(T x, T^{2} x\right) \leq k d(x, T x)$ (2.1)

$\operatorname{maka} \bigcap_{i=1}^{p} A_{i} \neq \emptyset$.

\section{Bukti:}

Jika $k=0$, maka untuk setiap $x \in \bigcup_{i=1}^{p} A_{i}$ berdasarkan pertidaksamaan (2.1), diperoleh: $d\left(T^{2} x, T x\right) \leq 0 . d(T x, x)$, dan $d\left(T x, T^{2} x\right) \leq$ 0. $d(x, T x)$

yaitu,

$$
d\left(T^{2} x, T x\right)=d\left(T x, T^{2} x\right)=0
$$

Selanjutnya, karena $(X, d)$ merupakan ruang metrik $d q b$ maka berdasarkan definisi ruang metrik $d q b(d l)$ didapat

$$
T^{2} x=T x
$$

Atau dengan kata lain, $T(T x)=T x$. Hal ini berarti bahwa $T x$ adalah titik tetap untuk $T$.

Disisi lain, diketahui bahwa

$$
T\left(A_{i}\right) \subseteq A_{i+1} \text {, untuk setiap } 1 \leq i \leq p
$$$$
\text { dengan } A_{p+1}=A_{1} \text {; }
$$

Karena $x \in \cup_{i=1}^{p} A_{i}$, maka diperoleh $T x \in$ $\bigcap_{i=1}^{p} A_{i}$. Jadi, untuk $k=0$, maka $\bigcap_{i=1}^{p} A_{i} \neq \varnothing$.
Selanjutnya, untuk $k \in\left(0, \frac{1}{s}\right)$ dan untuk $x \in$ $\cup_{i=1}^{p} A_{i}$, dengan menggunakan pertidaksamaan (2.1), diperoleh:

$$
\begin{aligned}
d\left(T^{n+1} x, T^{n} x\right) \leq & k \cdot d\left(T^{n} x, T^{n-1} x\right) \\
\leq & k^{2} \cdot d\left(T^{n-1} x, T^{n-2} x\right) \leq \\
& \cdots \leq k^{n} \cdot d(T x, x)
\end{aligned}
$$

Selain itu diperoleh pula:

$$
\begin{aligned}
d\left(T^{n} x, T^{n+1} x\right) \leq & k \cdot d\left(T^{n-1} x, T^{n} x\right) \\
\leq & k^{2} \cdot d\left(T^{n-2} x, T^{n-1} x\right) \leq \\
& \cdots \leq k^{n} \cdot d(x, T x)
\end{aligned}
$$

Dari pertidaksamaan (2.2) dan (2.3) didapat:

$\lim _{n, m \rightarrow \infty} d\left(T^{n} x, T^{m} x\right)=0, \quad$ dan $\lim _{n, m \rightarrow \infty}^{n, m \rightarrow \infty} d\left(T^{m} x, T^{n} x\right)=0$

Dengan kata lain, $\left\{T^{n} x\right\}$ merupakan barisan Cauchy- $d q b$ dalam ruang metrik $d q b$ $\left(\cup_{i=1}^{p} A_{i}, d\right)$.

Perhatikan bahwa $\bigcup_{i=1}^{p} A_{i} \subseteq X$ dan $X$ lengkap maka $\left(\cup_{i=1}^{p} A_{i}, d\right)$ juga lengkap. Oleh karena itu $\left\{T^{n} x\right\}$ konvergen- $d q b$ ke suatu $z \in \cup_{i=1}^{p} A_{i}$. Selain itu, dari kondisi 1) karena $T^{n} x \subseteq A_{i}$, untuk setiap $i=1,2, \cdots, p$ dan karena $A_{i}$ tertutup untuk setiap $i=1,2, \cdots, p$, maka $z \in \bigcap_{i=1}^{p} A_{i}$ dengan demikian $\bigcap_{i=1}^{p} A_{i} \neq \emptyset$.

Berikut ini diberikan teorema yang telah dibahas oleh Klin-eam dan Suanoom[2], mengenai ketunggalan titik tetap di ruang metrik $d q b$ lengkap yang mensyaratkan pemetaannya memenuhhi kondisi kontraksi Banach siklik $d q b$.

Teorema 2.2 Diberikan ruang metrik $d q b$ lengkap $(X, d)$ dan himpunan-himpunan tertutup $A, B \subseteq X$. Jika pemetaan siklik $T$ memenuhi kondisi kontraksi Banach siklik dqb, maka T mempunyai titik tetap tunggal di $A \cap B$.

Selanjutnya diberikan teorema yang telah dibahas oleh Dolicanin,dkk [1] yang kemudian dibuktikan ekuivalen dengan Teorema 2.2 diatas.

Teorema 2.3 Diberikan ruang metrik $d q b$ lengkap $(X, d)$ dan bilangan $s \geq 1$. Apabila pemetaan $T: X \rightarrow X$ memenuhi kondisi

$$
d(T x, T y) \leq k d(x, y)
$$


untuk setiap $x, y \in X$, dan untuk suatu $k \in\left[0, \frac{1}{s}\right)$, maka $T$ mempunyai titik tetap tunggal di $X$.

Teorema 2.4. Teorema 2.2 jika dan hanya jika Teorema 2.3

\section{Bukti:}

$(\Rightarrow)$

Dibentuk himpunan $A_{i}=X$ untuk setiap $i=$ $1,2, \cdots, p$ seperti yang diketahui pada Teorema 2.2. maka jelas Teorema 2.3 terbukti.

$(\Leftarrow)$

Ambil sebarang $x \in \cup_{i=1}^{p} A_{i}$, maka dari Lemma 2.1, barisan $\left\{T^{n} x\right\}$ adalah barisan Cauchy $d q b$ sehingga $\bigcap_{i=1}^{p} A_{i} \neq \varnothing$. Selanjutnya, karena $\left(\cap_{i=1}^{p} A_{i}, d\right)$ adalah ruang metrik $d q b$ lengkap dan $T$ di $\left(\bigcap_{i=1}^{p} A_{i}, d\right)$ sehingga $d(T x, T y) \leq k d(x, y)$, untuk setiap $x, y \in$ $\bigcap_{i=1}^{p} A_{i}$ maka berdasarkan Teorema $2.3 \mathrm{~T}$ mempunyai titik tetap tunggal di $\bigcap_{i=1}^{p} A_{i}$. Dengan kata lain terbukti Teorema 2.2.

Berikut ini diberikan contoh sebagai ilustrasi dari Teorema 2.4 diatas.

Contoh 2.5 Diberikan $X=[-1,1]$ dan $T x=$ $-\frac{x}{5}$. Apabila $A=[-1,0]$ dan $B=[0,1]$ kemudian didefinisikan fungsi $d: X \times X \rightarrow$ $[0, \infty)$ dengan

$$
d(x, y)=|x-y|^{2}+\frac{|x|}{10}+\frac{|y|}{11}
$$

Maka $(X, d)$ merupakan ruang metrik $d q b$ dengan koefisien $s=2$. Dan $T$ mempunyai titik tetap tunggal di $A \cap B$.

\section{Bukti:}

Berdasarkan hipotesa, jelas bahwa $X=A \cup B$ dan $T(A) \subseteq B, T(B) \subseteq A$. Akan dibuktikan $d(T x, T y) \leq k d(x, y)$.

Diambil sembarang $x, y \in X$

$$
\begin{gathered}
d(T x, T y)=d\left(-\frac{x}{5},-\frac{y}{5}\right) \\
=\left|-\frac{x}{5}+\frac{y}{5}\right|^{2}+\frac{|x|}{50}+\frac{|y|}{55} \\
=\frac{1}{5}\left(\frac{1}{5}|x-y|^{2}+\frac{|x|}{10}+\frac{|y|}{11}\right) \\
\leq \frac{1}{5}\left(|x-y|^{2}+\frac{|x|}{10}+\frac{|y|}{11}\right) \\
\leq k d(x, y)
\end{gathered}
$$

Dengan $k \in\left[\frac{1}{5}, \frac{1}{2}\right] \subseteq\left[0, \frac{1}{s}\right]$. Dengan demikian semua kondisi pada Teorema 2.3 dipenuhhi, hal ini berarti $T$ mempunyai titik tetap tunggal di $X$. Oleh karena itu, berdasarkan Teorema 2.4, $T$ mempunyai titik tetap tunggal di $A \cap B$. Karena $A \cap B=\{0\}$, maka 0 adalah titik tetap tunggal yang dimaksud.

\section{Penutup}

Berdasarkan pembahasan yang telah dilakukan, dapat disimpulkan bahwa ketunggalan titik tetap di ruang metrik-dqb lengkap pada suatu pemetaan dapat dibuktikan tanpa mensyaratkan pemetaan tersebut memenuhi kondisi kontraksi Banach siklik.

\section{Referensi}

[1] Dolic'anin-Dekic', D. T. (2016). A note on recent cyclic fixed point results in dislocated quasi-b-metric spaces. Fixed point theory and applications, 74.

[2] Klin-eam, C, Suanoom, C. (2015). Dislocated quasi-b-metric spaces and fixed point theorems for cyclic contractions. Fixed point Theory and Applications, 74

[3] Basha, SS, Veeramani, P: Best proximity pair theorems for multifunctions with open fibres. J. Approx. Theory 103, 119-129 (2000)

[4] Enjouji, Y, Nakanishi, M, Suzuki, T: A generalization of Kannan's fixed point theorem. Fixed Point Theory Appl. 2009, Article ID 192872 (2009)

[5] Kikkawa, M, Suzuki, T: Some similarity between contractions and Kannan mappings. Fixed Point Theory Appl. 2008, Article ID 649749 (2008)

[6] Nakanishi, M, Suzuki, T: An observation on Kannan mappings. Cent. Eur. J. Math. 8, 170178 (2010)

[7] Reich, S: Kannan's fixed point theorem. Boll. Unione Mat. Ital. 4, 1-11 (1971)

[8] Shioji, N, Suzuki, T, Takahashi, W: Contractive mappings, Kannan mappings and metric completeness. Proc. Am. Math.Soc. 126, 3117-3124 (1998). doi:10.1090/S00029939-98-04605-X

[9] Banach, S: Sur les operations dans les ensembles abstraits et leur application aux 
equations integrales. Fundam.Math. 3, 133181 (1922)

[10] Kannan, R: Some results on fixed points - II. Am. Math. Mon. 76, 405-408 (1969)

[11] Kirk, WA, Srinivasan, PS, Veeramani, P: Fixed points for mapping satisfying cyclic contractive conditions. Fixed Point Theory 4, 79-89 (2003)

[12] Karapinar, E, Erhan, IM: Best proximity on different type contractions. Appl. Math. Inf. Sci. 5, 558-569 (2010)

[13] Wilson, WA: On quasi-metric spaces. Am. J. Math. 53(3), 675-684 (1931)

[14] Hitzler, P, Seda, A: Dislocated topologies. J. Electr. Eng. 51, 3-7 (2000)

[15] Zeyada, FM, Hassan, GH, Ahmad, MA: A generalization of fixed point theorem due to Hitzler and Seda in dislocatedquasi-metric space. Arab. J. Sci. Eng. 31, 111-114 (2005)

[16] Włodarczyk, K, Plebaniak, R, Banach, A: Best proximity points for cyclic and noncyclic set-valued relatively quasiasymptotic contractions in uniform spaces. Nonlinear Anal. 70, 3332-3341 (2009)

[17] Włodarczyk, K, Plebaniak, R, Banach, A: Erratum to: 'Best proximity points for cyclic and noncyclic set-valued relatively quasiasymptotic contractions in uniform spaces'. Nonlinear Anal. 71, 3585-3586 (2009)

[18] Włodarczyk, K, Plebaniak, R, Obczyłski, C: Convergence theorems, best approximation and best proximity for set-valued dynamic systems of relatively quasi-asymptotic contractions in cone uniform spaces. Nonlinear Anal. 72, 794-805 (2010)

[19] Włodarczyk, K, Plebaniak, R: Kannan-type contractions and fixed points in uniform spaces. Fixed Point Theory Appl.2011, 90 (2011)

[20] Włodarczyk, K, Plebaniak, R: Contractions of Banach, Tarafdar, Meir-Keller, 'Ciri'cJachymski-Matkowski and Suzuki types and fixed points in uniform spaces with generalized pseudodistances. J. Math. Anal. Appl. 404, 338-350 (2013)

[21] Włodarczyk, K, Plebaniak, R: Asymmetric structures, discontinuous contractions and iterative approximation of fixed and periodic points. Fixed Point Theory Appl. 2013, 128 (2013)

[22] Włodarczyk, K: Hausdorff quasi-distances, periodic and fixed points for Nadler type set- valued contractions in quasi-gauge spaces. Fixed Point Theory Appl. 2013, 239 (2013)

[23] Włodarczyk, K, Plebaniak, R: Dynamic processes, fixed points, endpoints, asymmetric structures and investigations related to Caristi, Nadler and Banach in uniform spaces. Abstr. Appl. Anal. 2015, Article ID 942814 (2015)

[24] Bakhtin, IA: The contraction principle in quasimetric spaces. In: Functional Analysis, vol. 30, pp. 26-37 (1989)

[25] Czerwik, S: Nonlinear set-valued contraction mappings in b-metric spaces. Atti Semin. Mat. Fis. Univ. Modena 46, 263-276 (1998) 